\title{
Carreira num call center: a realidade portuguesa
}

Maria da Conceição Pereira Ramos

Ana de Fátima Rodrigues Afonso

Universidade do Porto

\section{Resumo}

Atualmente, muitos jovens adultos com bastantes qualificações são excluídos do mercado de trabalho por este não estar adaptado às suas qualificações (BONO, 2000). O mercado dos call centers tem ocupado uma posição de destaque na geração de novos postos de trabalho (SILVA, 2006), onde muitos dos jovens que lá ingressam esperam que seja temporário, de passagem, enquanto não encontram um trabalho melhor (LOUÇÃ, 2012). No entanto, o temporário torna-se, por vezes, longo, devido às restrições atuais do mercado de trabalho, levando os trabalhadores a permanecer, contrato após contrato, adaptando-se como podem aos ritmos e exigências da profissão, e suportando a desvalorização social e o estigma sobre o trabalho que realizam e, assim, seguindo carreira (LOUÇÃ, 2012; ROQUE, 2013). Deste modo, surge o interesse de refletir acerca dos motivos que levam esses trabalhadores a desenvolver

74 carreira num call center.

Palavras-chave: Call center. Carreira. Emprego dos jovens.

\section{Career in a call center: the Portuguese reality}

\section{Abstract}

Nowadays many highly qualified young adults are excluded from the labor market, because they are not adapted to their qualifications (BONO, 2000). The call center market has occupied a prominent position in the generation of new jobs (SILVA, 2006), who enter it expect it to be temporary, in transit, until they find a better job (LOUÇÃ, 2012). However, the temporary becomes sometimes long, due to the current restrictions of the labor market, leading workers to remain, contract after contract, adapting as they can to the rhythms and demands of the profession, bearing the social devaluation and the stigma about the work they perform and, thus, pursuing this career (LOUCC̃̃, 2012; ROQUE, 2013). In this way, the interest of reflecting on the reasons that lead these workers to develop career in a call center appears.

Keywords: Call center. Career. Jobs for young adults. 


\section{Carrera en un call center: la realidad portuguesa}

\section{Resumen}

En la actualidad, muchos jóvenes altamente cualificados son excluidos del mercado de trabajo, por no estar adaptados a su cualificación (BONO, 2000). El mercado de call centers tiene una posición de foco en nuevas aperturas de trabajo (SILVA, 2006), donde muchos de los jóvenes que se unen a este tipo de trabajo esperan que sea una solución temporal, mientras que están buscando un mejor trabajo (LOUÇÃ, 2012). Sin embargo, dadas las restricciones actuales del mercado de trabajo, el temporal se convierte en más de lo esperado. Los trabajadores se ven obligados a permanecer, contrato tras contrato, adaptándose como pueden al ritmo y exigencias del trabajo, soportando la devaluación social y estigma sobre el trabajo que realizan, y, así, siguiendo carrera (LOUCCÃ, $2012 ;$ ROQUE, 2013 ). De este modo, surge el interés de reflexionar acerca de los motivos que llevan a estos trabajadores a desarrollar carrera en un call center.

Palabras clave: Call centers. Carrera. Empleo de los jóvenes.

\section{Introdução}

Vivencia-se uma época marcada por profundas transformações nas relações políticas, sociais, econômicas, laborais, e um mercado cada vez mais global e competitivo, onde as pessoas devem se posicionar, sobressaindo nas organizações, principalmente porque a maioria das organizações não está preparada para agir, rapidamente, perante o ritmo dessas mudanças. Um dos efeitos dessas transformações é a falta de emprego nos diversos setores da economia, sendo essencial que as pessoas assumam, nas organizações, o seu papel de responsabilidade, qualificando-se e estimulando a qualificação para a manutenção da sua empregabilidade. Para as organizações, já não basta reduzir custos, urge reinventar o já existente, e isso requer modificações nas funções e comportamentos dos trabalhadores (MINARELLI, 1995).

Toda a (r)evolução laboral e organizacional das últimas décadas tem consequências na gestão das carreiras dos indivíduos, uma vez que os seus objetivos podem alterar-se ao longo do tempo. Há alguns anos, as decisões de carreira eram maioritariamente baseadas em questões relacionadas ao trabalho. Atualmente, é necessário ter em conta outras características, como, por 
exemplo, o estilo de vida do indivíduo, que pode ter um peso considerável nas decisões e escolhas de carreira (WILSON; DAVIES, 1999).

Por outro lado, essas mudanças trouxeram insegurança aos trabalhadores relativamente aos seus empregos, principalmente quanto à sua estabilidade, às suas capacidades e às suas oportunidades de carreira (ADAMS, 1991; SPARROW, 1996; SPARROW, COOPER, 1998; COOPER, 1999; LITTLER, 2000 apud FERREIRA, 2007), levando a uma redução da confiança, da satisfação com o trabalho, da motivação e do empenho (ROBINSON, 1996; HENDRY, JENKINS, 1997; LITTLER, 2000 apud FERREIRA, 2007). Consequentemente, surgem os sentimentos de um emprego menos seguro e de menor lealdade para com o empregador, que modificam as perceções do trabalhador acerca do que a organização the deve e do que este deve à organização, acarretando, por sua vez, uma maior responsabilidade do indivíduo na gestão da sua própria carreira (FERREIRA, 2007). Surge, assim, o termo "caos de carreira", que significa o fim das carreiras sólidas e duradouras, carreiras autodirigidas e compartilhadas com diversas empresas (MCDANIELS; GYLBERS, 1992; CHANLAT, 1995; FREITAS, 1997; AMHERDT, 1999 apud SANT'ANNA; CASTILHO; KILIMNIK, 2006).

\section{Desemprego jovem e empregabilidade}

O termo "desemprego" é bastante vasto; portanto, difícil de the atribuir uma única definição. Contudo, para o presente estudo, é pertinente considerar que o desempregado é o indivíduo que, pertencente à população ativa lem idade de trabalho), está à procura de trabalho remunerado e não o encontra. A taxa de desemprego trata-se, portanto, do rácio entre a população desempregada e a população ativa (Instituto Nacional de Estatística).

Nos últimos anos, verificou-se, em Portugal, um aumento muito acentuado da taxa de desemprego jovem, entre os 15 e os 24 anos, muito próxima dos 40\%, em 2012 (SÁ, 20 14), mas ainda muito elevada em 2013 e 2014 (INSTITUTO NACIONAL DE ESTATÍSTICA, 2014). Neste sentido, e tendo em conta a população jovem, nomeadamente na União Europeia e durante a crise, depara-se cada vez mais, com jovens que, provavelmente, devido às altas taxas de desemprego, procuram emprego em áreas que, à primeira vista, nada têm a ver com a sua formação escolar ou interesses e competências, 
com objetivos monetários e de sobrevivência, apesar das condições de trabalho precárias (CORRAL; ISUSI, 2013). Na jornada da vida profissional e acadêmica, muitos desses jovens continuam à procura de realização pessoal/ profissional, mas outros descobrem competências e aptidões que não pensavam ter, muitas vezes em momentos tardios após o ingresso no ensino superior ou já no mercado de trabalho, acabando por, de alguma forma, alterar o seu percurso profissional e motivações futuras.

Situações de escassez de oferta de emprego e/ou procura em excesso conduzem a uma subvalorização das qualificações dos trabalhadores, colocando, muitas vezes, jovens licenciados em funções que requerem níveis mais baixos de qualificações (RAMOS, 2003; CEDEFOP, 2015 ).

Nos últimos anos, Portugal tem assistido a um aumento muito acentuado da taxa de desemprego jovem, atingindo os 32,2\%, no 3. ${ }^{\circ}$ trimestre de 2014 (INSTITUTO NACIONAL DE ESTATÍSTICA, 2014). Apesar dos ligeiros recuos em 2015, chegou-se ao término do ano de 2014 com uma taxa de $34,8 \%$. Esses números são preocupantes, principalmente porque o desemprego tem atingido não só os indivíduos pouco qualificados, como também, inversamente, os mais qualificados, nomeadamente licenciados (SÁ, 2014). Em 2014, a percentagem de licenciados desempregados era de 10\% enquanto a de indivíduos com o ensino secundário ou pós-secundário de 15,3\% (INSTITUTO NACIONAL DE ESTATíSTICA, 2014). Durante algum tempo, atribuiu-se, como causa do desemprego jovem, as baixas qualificações, no entanto, hoje, sabe-se que não é verdade, já que o número de jovens qualificados desempregados tem aumentado ao longo dos anos (SÁ, 20 14). Assim, e, em face do crescente desemprego, os Call Centers podem considerar-se, por um lado, um escape laboral; por outro, uma rampa de inserção no mercado de trabalho (ROQUE, 2013).

\section{Call centers em Portugal}

De acordo com a Associação Portuguesa de Contact Centers (APCC) (2013), esse setor é um dos que mais disponibiliza postos de trabalho na sociedade atual, e o número continua a crescer em Portugal. $\bigcirc$ Call Center é um local de trabalho onde os operadores, através de um computador, recebem e fazem chamadas que são processadas e controladas por um programa 
de distribuição ou de realização automática de chamadas (CHAMBEL; CASTANHEIRA, 2010). As empresas de call center recorrem ao uso intensivo de tecnologias de informação e comunicação (PINTO, 2013), sendo a partir da década de 80, com a grande evolução das tecnologias de informação e comunicação, que os call centers se tornaram numa das áreas empresariais mais proeminentes, quer para venda de serviços, quer para o apoio a clientes (CASTELLS, 1997; ROQUE, 2013 ), funcionando como um paradoxo, visto que se trata de um dos meios laborais, quer de entrada, quer de saída, mais facilitados do mercado laboral (ROQUE, 2013).

Habitualmente, uma empresa de Call Center necessita de estar em constante adaptação, uma vez que as campanhas ou produtos que os operadores têm de promover podem ser variados e mudar ao longo do tempo com bastante frequência. Uma outra característica presente nos call centers é que essas empresas, devido à evolução tecnológica, podem facilmente deslocalizar-se, mantendo os mesmos serviços. A gestão dos recursos humanos é também muito flexível e diversa, sendo frequente muitos call centers recorrerem a empresas de recursos humanos para a gestão dos seus operadores, não tendo, assim, uma relação contratual direta com os operadores (ROQUE, 78 20131, que estão subordinados a padrões exigentes de controlo, produtividade e rotatividade.

De acordo com Bono (2000) e Roque (2013), os operadores de Call Center são maioritariamente jovens (com idade entre os 20 e os 30 anos), estudantes universitários ou à procura do primeiro emprego, embora exista uma percentagem crescente de jovens e mulheres que mantêm essa atividade durante alguns anos por inexistência de trabalho mais adequado (SILVA, 2006). Apesar disso, seguno Roque (2013), esse tipo de trabalho é cada vez mais procurado por pessoas mais velhas. Relativamente às qualificações exigidas, normalmente estas são elevadas, uma vez que os operadores têm de dominar plataformas informáticas, embora muitos não sintam qualquer reconhecimento social relativamente ao seu trabalho (SANTOS; MARQUES, 2006).

Bono (2000, p. 18) refere que a ligação dos operadores de Call Center à empresa pode, em alguns aspectos, parecer-se com a ligação que os trabalhadores das organizações tayloristas mantinham com estas, nomeando os Call Centers "[...] linhas de montagem do século XXI [...]", pois os trabalhadores definem o seu trabalho como monótono, enfadonho e fonte de grande stress. Segundo o estudo de Santos e Marques (2006), muitos operadores 
(cerca de 46\%, a maioria jovens e mulheres) escolhem esse trabalho por ser desempenhado em part time, sendo visto, apenas, como forma de ganhar dinheiro quando necessitam pagar os estudos ou enquanto não surge uma oportunidade de um emprego "melhor".

A esse tipo de trabalho está quase sempre associada uma imagem negativa, uma vez que as condições laborais geram elevados níveis de stress, de insatisfação e de desinvestimento no trabalho e na atividade profissional (CHAMBEL; CASTANHEIRA, 2010). Para a investigadora Rosenfield (ANTUNES; BRAGA, 2009), o trabalho em Call Center traduz-se numa fragilidade identitária dos trabalhadores, resultado da ausência de valorização social do trabalho dos operadores de telemarketing e da sua associação a técnicas de venda pouco escrupulosas. A investigadora considera ainda que as identidades são sempre provisórias, quer para os operadores que procuram realização pessoal fora do Call Center, supondo ser um emprego de passagem, quer para os que investem o seu esforço na função, devido à ausência de perspectivas de construção de carreira e à alta rotatividade desses empregos.

De acordo com Bono (2000) e Bono e Bulloni (2008), os Call Centers representam o emprego do futuro, pois, além do escape temporário considerado por alguns operadores, são o emprego permanente para muitos indivíduos que se "resignam" com a precariedade laboral e onde acabam por fazer carreira.

Diversos estudos apontam que os trabalhadores mais envolvidos tendem a ser menos absentistas, a desejar manter o emprego, a sentir maior satisfação com o trabalho e a ter um melhor desempenho (CHAMBEL, CASTANHEIRA, 2010; CASTANHEIRA, CHAMBEL, 20121.

Segundo Roque (2013), a identidade do operador de call center é caracterizada pela inexistência de expectativas e pela frustração, não havendo por parte deste identificação com a construção de uma carreira profissional, tampouco um sentimento de pertença à empresa para a qual trabalha. De acordo com Huws (2001 apud ROQUE, 2013) e Standing (201 1 apud ROQUE, 20131 , o operador de call center promove formas de trabalho inseguras, tornando-se difícil a construção da sua identidade ocupacional, assim como da sua carreira profissional (ROQUE, 2013).

Segundo o Sindicato dos Trabalhadores de Call Center em Portugal (STCC), as más condições de trabalho são uma queixa recorrente, sobressaindo 
a falta de progressão na carreira, a rígida supervisão, a pressão, a instabilidade e o assédio moral.

\section{Conceito de "carreira profissional"}

De acordo com Martins (2001), etimologicamente, a palavra "carreira" deriva do latim via "carraria", "estrada". Só a partir do século XIX, se inicia a utilização da palavra com o significado de "trajetória de vida profissional", que até, recentemente, era da responsabilidade das organizações, das quais o indivíduo saberia, de antemão, o que esperar quanto ao seu percurso profissional. Segundo Dutra (1996), a definição de "carreira" é uma sequência de fases complexas, quando são atribuídas mais responsabilidades aos trabalhadores.

Numa perspectiva mais tradicional, a carreira pode ser vista enquanto desenvolvimento profissional, através do qual se vai ascendendo, hierarquicamente, numa determinada organização ao longo da vida (WILENSKY, 1961 apud CUNHA; REGO; CUNHA; CABRAL-CARDOSO; MARQUES; GOMES,

8020121 . Deste modo, os trabalhadores pressupõem que, ao longo da sua atividade profissional, vão desenvolvendo tarefas cada vez mais complexas, de maior responsabilidade e, sobretudo, de maior prestígio (MARTIN, STRAUSS, 1956; WILENKY, 1961; STEWMAN; KONDA, 1983 apud CUNHA; REGO; CUNHA; CABRAL-CARDOSO; MARQUES; GOMES, 20121. Apesar disso, existe, para algumas funções, de acordo com Thomas (1989 apud CUNHA; REGO; CUNHA; CABRAL-CARDOSO; MARQUES; GOMES, 2012) e Hennequin (2007 apud CUNHA; REGO; CUNHA; CABRAL-CARDOSO; MARQUES; GOMES, 20121, a possibilidade da progressão de carreira horizontal na hierarquia organizacional (CUNHA; REGO; CUNHA; CABRAL-CARDOSO; MARQUES; GOMES, 2012). Não obstante, a noção de "carreira" também traz, implícita a ideia de esforço e dedicação ao trabalho numa determinada atividade (GREENHAUS; CALLANAN, 1994), pelo que não se está perante a necessidade de haver uma única organização como empregador, mas da conjugação de dois aspectos: o aproveitamento das oportunidades do mercado de trabalho e a vontade e interesses do trabalhador (CUNHA; REGO; CUNHA; CABRALCARDOSO; MARQUES; GOMES, 20121. 
Assim, a carreira de um indivíduo não é necessariamente igual à carreira de outro na mesma profissão. "Tal como não existem duas viagens iguais, também cada carreira é uma experiência única e, em boa parte, imprevisível: o caminho faz-se caminhando [...]" (CUNHA; REGO; CUNHA; CABRAL-CARDOSO; MARQUES; GOMES, 2012 , p. 584). Surge, entretanto, uma outra visão de carreira, entendida como sequência de experiências profissionais ocorridas ao longo da vida, em que existem modificações nos desejos, concepções e atitudes (COLLIN; WATTS, 1996; BIRD 1996 apud COHEN, 2001, apud CUNHA; REGO; CUNHA; CABRAL-CARDOSO; MARQUES; GOMES, 20121.0 desenvolvimento de uma carreira é, portanto, um conjunto de processos e não de acontecimentos isolados. Para algumas pessoas, esse processo pode até parecer linear, mas, para outros, existem muitas regressões, escaladas, "becos sem saída", momentos de confusão e de acalmia (NÓVOA, 2000).

$\bigcirc$ conceito de "gestão de carreira" tem subjacente a necessidade que cada ser humano tem de realização pessoal, mas pretende responder igualmente às necessidades dos recursos humanos das organizações (CUNHA; REGO; CUNHA; CABRAL-CARDOSO; MARQUES; GOMES, 201 21. De acordo com Greenhaus e Callanan (1994), a gestão de carreira é considerada um processo de resolução de problemas, em que os indivíduos adquirem informação pelo conhecimento da carreira e desenvolvem uma maior consciência de si mesmos e do ambiente que os rodeia, criando estratégias de desenvolvimento da sua carreira. Na literatura, não está claro quem tem mais responsabilidade na gestão das carreiras: se os indivíduos, se as organizações. Neste sentido, parece prevalecer que a gestão da carreira deve ser considerada uma responsabilidade partilhada em que ambos se influenciam e podem sair beneficiados. Por um lado, permite às organizações motivar e reter os bons colaboradores; por outro, os indivíduos têm poder de decisão e de escolha (CUNHA; REGO; CUNHA; CABRAL-CARDOSO; MARQUES; GOMES, 20121.

Savickas, Silling e Schwartz (1984 apud JANEIRO, 2010) chamam a atenção para a importância da capacidade que o ser humano tem em perspectivar o futuro, visto que verificaram correlações entre as atitudes de planeamento de carreira e algumas dimensões da perspectiva temporal, ou seja, o grau de estruturação do futuro, como eventos e a expectativa otimista do futuro (JANEIRO, 2010).

Já praticamente nenhuma empresa oferece uma carreira longa e estável, e, nestes tempos modernos de alta competitividade, é preciso perceber 
que não se deve deixar para a organização a obrigação de cuidar da carreira dos seus colaboradores. No passado, a empresa era responsável pelo crescimento profissional dos seus trabalhadores, procurando ingressar numa boa empresa visando garantir o seu futuro. Atualmente, a realidade é bem diferente, não se trabalha, apenas, para o desenvolvimento da empresa, mas também para o desenvolvimento humano, ou seja, o desenvolvimento de cada um dos colaboradores (BECKHARD, 1997).

\section{Metodologia de investigação}

Dutra (1996) considera que os estudos concernentes à carreira são importantes, tanto para as empresas como para os trabalhadores, no sentido de compreender melhor a realidade em que estão inseridos, minimizando situações que possam levar a perdas, sofrimentos e riscos para ambas as partes.

De acordo com Sousa e Baptista (201 1), a metodologia escolhida numa investigação deve levar em conta o seu objetivo, para que ele seja mais bem compreendido. Nesse sentido, a metodologia utilizada no presente traba-

82 tho recorre ao estudo qualitativo, tendo como objeto de análise treze entrevistas semiestruturadas envolvendo profissionais (com funções além de operadores) de dois call centers da região do Porto, em Portugal.

Os dados recolhidos foram posteriormente explorados com recurso à análise de conteúdo, um método muito utilizado no âmbito da investigação qualitativa. A análise de conteúdo é uma técnica de investigação empírica, definida por Berelson (1952, 1968 apud CARMO; FERREIRA, 1998, p. 251 ) como "[...] uma técnica de investigação que permite fazer uma descrição objetiva, sistemática e quantitativa do conteúdo manifesto das comunicações, tendo por objetivo a sua interpretação". Hoje, assume-se mais como

[...] um conjunto de técnicas de análise das comunicações visando obter, por procedimentos sistemáticos e objetivos de descrição do conteúdo das mensagens, indicadores (quantitativos ou não) que permitam a inferência de conhecimentos relativos às condições de produção/receção (variáveis inferidas) destas mensagens (BARDIN, 2014, p. 42). 
Com esse projeto, pretende-se analisar o modo como diferentes profissionais de Call Center de uma organização percebem a sua carreira profissional na área e, assim, conhecer, compreender e interpretar como surgem as carreiras num Call Center, do ponto de vista desses profissionais, já que, para muitos, a escolha dessa profissão é um último recurso, num mercado laboral com escassez de oportunidades de emprego e trabalho precário. Dessa forma, foi elaborada a seguinte grelha de análise de conteúdo:

\section{Quadro 1}

Análise de conteúdo

\begin{tabular}{|c|c|}
\hline Categorias & Subcategorias \\
\hline Escolaridade & $\begin{array}{c}\text { Grau obtido } \\
\text { Frequência atual } \\
\text { Investimento em formação }\end{array}$ \\
\hline Experiência profissional anterior & $\begin{array}{c}\text { Oportunidade na área de formação } \\
\text { Setor profissional } \\
\text { Função desempenhada } \\
\text { Duração da experiência } \\
\text { Relação contratual } \\
\text { Motivo da escolha } \\
\text { Motivo da saída } \\
\end{array}$ \\
\hline $\begin{array}{l}\text { Experiência profissional em call } \\
\text { center }\end{array}$ & $\begin{array}{c}\text { Motivo de entrada } \\
\text { Função de entrada e duração } \\
\text { Relação contratual } \\
\text { Motivo da mudança de categoria } \\
\text { Tempo na função } \\
\text { Remuneração }\end{array}$ \\
\hline Família & $\begin{array}{c}\text { Estado civil } \\
\text { Filhos } \\
\text { Importância da conciliação trabalho/ } \\
\text { família }\end{array}$ \\
\hline Perspectivas de future & $\begin{array}{c}\text { Precariedade vs. Estabilidade } \\
\text { Gosto pela função } \\
\text { Regularidade financeira } \\
\text { Ausência de oportunidades }\end{array}$ \\
\hline Carreira profissional & $\begin{array}{c}\text { Definição } \\
\text { Expectativas pessoais }\end{array}$ \\
\hline
\end{tabular}




\section{Caracterização da amostra}

A amostra é composta por treze entrevistados, com mais de um ano de experiência profissional em Call Center. Com o propósito de ir ao encontro dos objetivos deste estudo, a amostra foi previamente selecionada, levando em conta a categoria profissional dos entrevistados (não foram entrevistados operadores de Call Center).

Os entrevistados são profissionais de dois Call Centers situados no Porto, cuja principal atividade é o outbound (vulgarmente conhecido como telemarketing, ou seja, os operadores têm, como função principal, vender produtos) na área das telecomunicações. Apesar de também existir inbound (vulgarmente conhecido como "atendimento ao cliente": queixas, reclamações, apoio técnico), não foi entrevistado nenhum profissional dessa área.

No quadro que sequente, é apresentado um breve resumo acerca de cada entrevistado, nomeadamente idade, gênero, estado civil, escolaridade e função desempenhada.

Quadro 2

Caracterização da amostra

\begin{tabular}{|c|c|c|c|c|c|}
\hline Entrevistado & Idade & Gênero & Estado Civil & Escolaridade & Função \\
\hline 1 & 27 & $F$ & União fato & Mestrado & Backoffice \\
\hline 2 & 26 & M & Solteiro & $\begin{array}{c}\text { Ensino } \\
\text { secundário }\end{array}$ & $\begin{array}{l}\text { Chefe } \\
\text { equipa }\end{array}$ \\
\hline 3 & 31 & $\mathrm{~F}$ & Solteiro & Mestrado & Supervisor \\
\hline 4 & 35 & M & Divorciado & $\begin{array}{l}\text { Ensino } \\
\text { secundário }\end{array}$ & $\begin{array}{l}\text { Chefe } \\
\text { equipa }\end{array}$ \\
\hline 5 & 29 & M & Solteiro & $\begin{array}{c}\text { Ensino } \\
\text { secundário }\end{array}$ & $\begin{array}{l}\text { Chefe } \\
\text { equipa }\end{array}$ \\
\hline 6 & 40 & $F$ & Solteiro & $\begin{array}{l}\text { Ensino } \\
\text { secundário }\end{array}$ & Formador \\
\hline 7 & 24 & M & Solteiro & Licenciatura & $\begin{array}{l}\text { Chefe } \\
\text { equipa }\end{array}$ \\
\hline 8 & 24 & M & Casado & $\begin{array}{l}\text { Ensino } \\
\text { secundário }\end{array}$ & Auditor \\
\hline
\end{tabular}




\section{Quadro 2}

Caracterização da amostra

\begin{tabular}{|c|c|c|c|c|c|}
\hline Entrevistado & Idade & Gênero & Estado Civil & Escolaridade & Função \\
\hline 9 & 23 & $F$ & União fato & Licenciatura & Backoffice \\
\hline 10 & 24 & $M$ & União fato & $\begin{array}{c}\text { Ensino } \\
\text { secundário }\end{array}$ & $\begin{array}{c}\text { Chefe } \\
\text { equipa }\end{array}$ \\
\hline 11 & 29 & $M$ & Solteiro & $\begin{array}{c}\text { Ensino } \\
\text { secundário }\end{array}$ & $\begin{array}{c}\text { Chefe } \\
\text { equipa }\end{array}$ \\
\hline 12 & 30 & $M$ & Solteiro & $\begin{array}{c}\text { Ensino } \\
\text { secundário }\end{array}$ & $\begin{array}{c}\text { Chefe } \\
\text { equipa }\end{array}$ \\
\hline 13 & 28 & $M$ & Solteiro & $\begin{array}{c}\text { Ensino } \\
\text { secundário }\end{array}$ & $\begin{array}{c}\text { Chefe } \\
\text { equipa }\end{array}$ \\
\hline
\end{tabular}

Dos treze profissionais de Call Center entrevistados, apenas quatro são do sexo feminino, permitindo verificar que existe uma maior predominância do gênero masculino nos cargos "acima" de operador. Relativamente à idade, verifica-se que os entrevistados são todos bastante jovens, a maioria de idade inferior a 30 anos. $\bigcirc$ entrevistado mais novo tem 23 anos e o mais velho 40, sendo a média de idades de 28 anos e a moda de 24 anos. Relativamente ao estado civil, constata-se que a maioria dos elementos desse grupo $(69,23 \%)$ são solteiros, os demais são casados ou estão em união de fato, apenas um é divorciado. No que toca à escolaridade, a maioria tem o ensino secundário $(69,23 \%)$, sendo que dois deles frequentam, atualmente, o ensino superior e quatro possuem grau de licenciado e/ou mestrado.

Relativamente à função desempenhada, verifica-se a existência de cinco funções distintas: backoffice, formador, auditor, chefe de equipa e supervisor. Dessas funções, na amostra, destacou-se, claramente, a função de chefe de equipa (61,54\%), seguindo-se dois backoffice, e apenas um entrevistado para cada uma das restantes funções. Tendo em conta o conhecimento da organização de um Call Center, sabe-se que a maioria dos profissionais são operadores, estando na base da pirâmide, seguindo-se a função de chefe de equipa. Pensado numa progressão hierárquica em pirâmide, o chefe de equipa está no segundo nível, juntamente com o backoffice e o auditor. No terceiro nível, encontra-se o supervisor (por área de negócio), podendo encontrar aqui, também, o formador. 


\section{Análise e discussão dos resultados}

No que diz respeito à categoria "escolaridade", verifica-se que o grupo de entrevistados tem, pelo menos, o ensino secundário concluído, dos quais dois estão, atualmente, frequentando o ensino superior e quatro têm a licenciatura ou mestrado concluído. Nenhum dos entrevistados está estudando ou estudou na área comercial; as áreas de estudo dessa amostra são educação social, direito, engenharia biomédica (ainda a frequentar), design, gestão (ainda a frequentar) e engenharia química. A maioria dos entrevistados com o ensino secundário concluído pondera candidatar-se à universidade, não estando porém para seus objetivos. Todos os entrevistados afirmaram não investir, por iniciativa própria, em formação, quer na área das vendas, quer na área do Call Center, mas todos tiveram formação fornecida pela empresa das telecomunicações. Relativamente aos entrevistados que não continuaram os estudos, estes referiram principalmente dois motivos para o afastamento académico: as dificuldades financeiras da família e a dificuldade em conciliar estudos com a vida profissional. Relativamente à primeira experiência profissional dos entrevistados, foi elaborado o seguinte quadro com o seu resumo.

Quadro 3

Primeira experiência profissional dos entrevistados

\begin{tabular}{|c|c|c|c|c|}
\hline Entrevistado & $\begin{array}{c}\text { Idade início } \\
\text { funções }\end{array}$ & Função & Duração & Motivo de saída \\
\hline 1 & 20 anos & $\begin{array}{c}\text { Vendedor } \\
\text { porta a porta }\end{array}$ & 0,5 ano & $\begin{array}{c}\text { Estágio da } \\
\text { licenciatura }\end{array}$ \\
\hline 2 & 18 anos & $\begin{array}{c}\text { Operador call } \\
\text { center }\end{array}$ & 1 ano & $\begin{array}{c}\text { Entrada na } \\
\text { faculdade }\end{array}$ \\
\hline 3 & 20 anos & Investigador & 3 anos & $\begin{array}{c}\text { Fim } \\
\text { financiamento }\end{array}$ \\
\hline 4 & 18 anos & Caixeiro & 4,5 anos & Melhor oferta \\
\hline 5 & 19 anos & $\begin{array}{c}\text { Empregado } \\
\text { restauração }\end{array}$ & 1 ano & $\begin{array}{c}\text { Salário baixo, } \\
\text { não gostava }\end{array}$ \\
\hline 6 & 18 anos & $\begin{array}{c}\text { Empregado } \\
\text { restauração }\end{array}$ & 1 ano & Não gostava \\
\hline
\end{tabular}




\section{Quadro 3}

Primeira experiência profissional dos entrevistados

\begin{tabular}{|c|c|c|c|c|}
\hline Entrevistado & $\begin{array}{c}\text { Idade início } \\
\text { funções }\end{array}$ & Função & Duração & Motivo de saída \\
\hline 7 & 18 anos & $\begin{array}{c}\text { Design } \\
\text { interiores }\end{array}$ & 1 ano & Salário baixo \\
\hline 8 & 22 anos & Comercial & 1 ano & Fim contrato \\
\hline 9 & 20 anos & Operador loja & 0,5 ano & Fim contrato \\
\hline 10 & 18 anos & $\begin{array}{c}\text { Empregado } \\
\text { restauração }\end{array}$ & 2 anos & $\begin{array}{c}\text { Mudança } \\
\text { residência }\end{array}$ \\
\hline 11 & 19 anos & $\begin{array}{c}\text { Operador Call } \\
\text { Center }\end{array}$ & 3 anos & $\begin{array}{c}\text { Nova } \\
\text { Oportunidade/ } \\
\text { Cansaço da } \\
\text { função }\end{array}$ \\
\hline 12 & 18 anos & $\begin{array}{c}\text { Operador Call } \\
\text { Center }\end{array}$ & 1,5 anos & $\begin{array}{c}\text { Cansaço da } \\
\text { função }\end{array}$ \\
\hline 13 & 20 anos & $\begin{array}{c}\text { Operador } \\
\text { loja }\end{array}$ & 1,5 anos & Fim contrato \\
\hline
\end{tabular}

Na maioria dos casos $(76,9 \%)$, a primeira experiência profissional não foi em Call Center, mas em áreas diferentes, desde a hotelaria à construção civil, setores de empregabilidade "aberta" e de importantes variações sazonais e conjunturais da atividade económica. Apenas três entrevistados tiveram num Call Center, como operador, a sua primeira experiência profissional. É possível, também, verificar que cerca de metade começou a trabalhar muito jovem, com 18 anos, sendo a média de idade de início da atividade profissional de 19 anos. Os primeiros empregos dessa amostra são maioritariamente empregos pouco qualificados. Com essa análise, pode-se verificar que os principais motivos de abandono das primeiras experiências profissionais devem-se tanto ao fato de os contratos de trabalho terem caducado, como ao de os entrevistados procurarem um trabalho com uma remuneração mais atrativa. Refira-se a importância dos contratos precários, sobretudo nos jovens e no trabalho em geral (SÁ, 2014; CORRAL, ISUSI, 2013), estando Portugal entre os países da União Europeia onde o índice de precariedade é dos mais elevados. 
Visando ficar mais perceptivo o percurso profissional dos entrevistados dentro do Call Center atual, elaborou-se este pequeno quadro-resumo relativamente à função desempenhada quando entraram no Call Center, a sua duração, a função atual e a antiguidade.

Quadro 4

Resumo da experiência dos entrevistados no Call Center atual

\begin{tabular}{|c|c|c|c|c|c|}
\hline Entrevistado & $\begin{array}{c}\text { Início funções } \\
\text { no CC }\end{array}$ & Função & Duração & Função atual & Duração \\
\hline 1 & 2010 & $\begin{array}{l}\text { Operador } \\
\text { inbound }\end{array}$ & 3 anos & Backoffice & 2,5 anos \\
\hline 2 & 2013 & $\begin{array}{l}\text { Operador } \\
\text { outbound }\end{array}$ & 1 ano & Chefe equipa & 1 ano \\
\hline 3 & 2011 & $\begin{array}{l}\text { Operador } \\
\text { outbound }\end{array}$ & 2 anos & Supervisor & 2 anos \\
\hline 4 & 2010 & $\begin{array}{l}\text { Operador } \\
\text { outbound }\end{array}$ & 3 anos & Chefe equipa & 2 anos \\
\hline 5 & 2007 & $\begin{array}{l}\text { Operador } \\
\text { inbound }\end{array}$ & 4,5 anos & Chefe equipa & 1 ano \\
\hline 6 & 2001 & $\begin{array}{l}\text { Operador } \\
\text { inbound }\end{array}$ & 7 anos & Formador & 0,5 ano \\
\hline 7 & 2012 & $\begin{array}{l}\text { Operador } \\
\text { outbound }\end{array}$ & 2 anos & Chefe equipa & 1 ano \\
\hline 8 & 2014 & $\begin{array}{l}\text { Operador } \\
\text { outbound }\end{array}$ & 0,5 ano & Auditor & 1 ano \\
\hline 9 & 2013 & $\begin{array}{l}\text { Operador } \\
\text { inbound }\end{array}$ & 0,5 ano & Backoffice & 2,5 anos \\
\hline 10 & 2009 & $\begin{array}{l}\text { Operador } \\
\text { outbound }\end{array}$ & 1 ano & Supervisor & 3 anos \\
\hline 11 & 2012 & Chefe equipa & - & - & 3 anos \\
\hline 12 & 2013 & Chefe equipa & - & - & 2 anos \\
\hline 13 & 2010 & $\begin{array}{l}\text { Operador } \\
\text { outbound }\end{array}$ & 1 ano & $\begin{array}{l}\text { Chefe } \\
\text { equipa }\end{array}$ & 3 anos \\
\hline
\end{tabular}

No que se refere à função de entrada no Call Center atual, apenas dois operadores entraram diretamente para chefe de equipa. Em ambos os 
casos, os entrevistados já tinham trabalhado na área das telecomunicações como operadores de Call Center (noutro Call Center), tendo, ao longo das suas experiências profissionais, desempenhado também funções de chefes de equipa. Os restantes dos entrevistados entraram no Call Center como operadores e só posteriormente passaram para outros cargos. Os motivos anunciados para a entrada nessa área são diversos, mas a maioria aponta o fato de haver se candidatado ao cargo por indicação de um amigo ou através da candidatura a uma vaga anunciada publicamente, numa situação em que estavam desempregados e à procura de novo emprego.

Verificado por Roque (2013) na sua investigação, todos os entrevistados têm a sua relação contratual com uma empresa de recursos humanos, cujo primeiro contrato foi um contrato de formação, passando, depois, para contrato a termo incerto ou a termo certo renovável automaticamente. Apenas um dos entrevistados iniciou a sua relação contratual num Call Center com recibos verdes e outro sem qualquer relação laboral.

Conforme já referido, a maioria dos entrevistados exerce, atualmente, a função de chefe de equipa. Quando questionados acerca dos motivos da mudança de categoria profissional, a maioria refere o seu bom desempenho enquanto operador, com bons resultados nas vendas, e a dedicação ("entrega") ao trabalho. Para a maioria dos entrevistados, a mudança de categoria profissional foi entendida como uma promoção, cujos critérios para a sua escolha foram, essencialmente, os resultados alcançados enquanto operadores. Os entrevistados que não partilham dessa opinião relatam que a mudança de categoria foi um aproveitamento das suas competências, ultrapassando a capacidade de vender.

Quanto à função desempenhada, atualmente, no Call Center e ao motivo que leva os entrevistados a aí permanecer, as respostas indicam a existência de um bom espírito de equipa em que todos se dão bem, sendo, igualmente, relatado como importante motivo de permanência a remuneração atrativa em face do mercado de trabalho existente em Portugal. Numa perspectiva global, os entrevistados gostam das funções que desempenham e do local onde estão trabalhando, chegando inclusive a estabelecer relações de amizade com os colegas de trabalho.

Todos os entrevistados relataram que, antes do início das suas funções, frequentaram formação. A formação que vai sendo desenvolvida no Call 
Center não é, geralmente, uma formação formal, mas os entrevistados consideram fundamental a sua existência para os bons resultados alcançados.

De acordo com os entrevistados, os salários só são diferenciados através do sistema de prémios e de complementos de função, também variáveis. O salário-base corresponde ao salário mínimo nacional para um trabalhador a full time, quer seja operador, auditor, backoffice ou chefe de equipa. A exceção está nos salários-base dos supervisores e formadores, que são um pouco mais elevados.

A maioria dos entrevistados considera que o aumento da remuneração não foi proporcional ao crescimento das responsabilidades, chegando mesmo um dos entrevistados a verbalizar que ganhava mais enquanto operador, pois vendia muito. Foi relatado pela maioria dos entrevistados que o vencimento médio do operador era inferior ao vencimento atual (seja qual for a função desempenhada). Como seria expectável, verifica-se que a função de supervisor é a mais bem remunerada, seguida da função de chefe de equipe.

Conforme abordado anteriormente, apenas três entrevistados estão casados ou em união de fato. Destes, um está aguardando a chegada do primeiro filho, outro afirma querer constituir família, embora ainda seja cedo, e o terceiro afirma não fazer parte dos seus planos para já ter filhos. $\bigcirc$ único operador com filhos afirmou que foi motivado pela família que veio para o Call Center, deixando o emprego que exercia havia 14 anos. É interessante verificar que, dos entrevistados, apenas um colaborador tem filhos, existindo um segundo aguardando a chegada do primeiro filho. A maioria dos entrevistados são solteiros, residindo sozinhos ou com os pais. Desse modo, é impossível aprofundar mais essa categoria, já que todos os candidatos indicaram como importante a conciliação família/trabalho, encontrando-se no entanto a residir sozinhos ou com os pais. Esse fato vai ao encontro dos dados que têm sido avançados, e bastante debatidos, na comunicação social e que são do conhecimento público e dos investigadores: em Portugal, os jovens iniciam o projeto familiar cada vez mais tarde, contando com a importante solidariedade familiar e das redes sociais informais para lidar com a crise, enfretando uma série de constrangimentos (GUERREIRO; ABRANTES, 2007). Em 2013, na União Europeia, os jovens portugueses eram os que saíam mais tarde de casa dos pais (com 29 anos, sendo a média para os 28 países da UE de 26, 1 anos) (EUROSTAT, 2015). Neste sentido, e de acordo com Sá (2014), a precariedade económica e social faz parte de muitas famílias portuguesas em que 
o trabalho precário e inseguro está associado à instabilidade de programar o futuro, principalmente para os jovens que ficam até mais tarde em casa dos pais, devido à dificuldade em enfrentar os riscos sociais; incapacidade de a família assumir as despesas diárias; e alterações constantes dos horários laborais e da relação entre o trabalho e o desemprego. Em Portugal, de acordo com Rebelo (2004), são as mulheres, os jovens, os idosos, os trabalhadores com baixa escolaridade e os licenciados os mais vulneráveis à precariedade laboral.

Relativamente às perspectivas futuras dos entrevistados, as opiniões dividem-se em dois tipos. Uma parte dos entrevistados indica pretender continuar a trabalhar na área das telecomunicações, mas não necessariamente em Call Center, uma vez que gosta do que fazem. Outros dizem não pretender continuar na área a longo prazo, almejando uma oportunidade na sua área de formação.

No que concerne à definição de "carreira profissional", tal como verificado na pesquisa bibliográfica realizada, para a maioria dos entrevistados não é uma definição fácil. É possível analisar, em cada uma das respostas, aspectos únicos e individuais em que a experiência profissional contribui, grandemente, para a noção de "carreira profissional". Não obstante, verifica-se, igualmente, alguns pontos em comum, ressalvando a ideia transversal de que, associados à definição de "carreira", se encontram conceitos como "progressão" (hierárquica ou de responsabilidades/tarefas) e "aumento salarial", como defende Dutra (1996), em que a carreira consiste numa sequência de fases com atribuição de maiores responsabilidades aos trabalhadores. Ao longo desse "caminho" individual, cada ser humano vai adquirindo experiência e competências que the permitem essa progressão (DUTRA, 1996).

Alguns dos entrevistados têm uma visão de carreira mais tradicional (WILENSKY, 1961, apud CUNHA; REGO; CUNHA; CABRAL-CARDOSO; MARQUES; GOMES, 20121 , definindo-a como "subir patamares [...] começar de baixo" (E 13; E10, 2015), "progredir" (E2; E5; E9, 2015), referindo-se à existência de uma progressão hierárquica em que os trabalhadores vão desenvolvendo tarefas mais complexas e com mais responsabilidade. Desse modo, e tal como indicado por Terenas (2012), a carreira profissional é entendida como um processo complexo de desenvolvimento ao longo da vida de um indivíduo em que aprendizagem exerce um papel preponderante: "[...] é aprender todos os dias e trabalhar para ser melhor [...]" (E4, 2015). Para o entrevistado 
E9 (2015), com o seu relato de carreira profissional, "[...] tem dois fatores muito importantes: bem-estar [...]" e "[...] melhores condições", e para o E 11 (2015), "[...] será desde o primeiro dia em que tive uma atividade que se possa considerar trabalho [...] é a minha bagagem", encaminha a sua visão para a possibilidade de a gestão de carreira ser feita pelo indivíduo, através da aquisição de estratégias que the permite construir carreira procurando o bem-estar e o desenvolvimento pessoal (GREENHAUS, CALLANAN, 1994; KOSSEK, ROBERTS, FISHER, DEMARR, 1998 apud FERREIRA, 2007; HALL, 1991 e 1996; HALL, MIRVIS, 1995; HALL, MOSS, 1998 apud CASTANHEIRA, CAETANO, 1999; CUNHA, REGO, CUNHA, CABRAL-CARDOSO, MARQUES, GOMES, 2012 . . Alguns dos entrevistados deixaram claro, nos seus depoimentos, a possibilidade de a carreira profissional não ocorrer numa única organização ou área profissional, indo ao encontro da definição de "carreira sem fronteiras" ou boundaryless career (ARTHUR, ROUSSEAU, 1996 a e $1996 \mathrm{~b}$ apud FERREIRA, 2007; CUNHA, REGO, CUNHA, CABRAL-CARDOSO, MARQUES, GOMES, 20121 , "[...] podendo ser numa só empresa ou dentro de uma área em várias empresas" (E8, 2015). Tal como para Cunha; Rego; Cunha; Cabral-Cardoso; Marques; Gomes (2012), a carreira "[...] é tudo o que é desenvolvimento 92 enquanto ser humano" (E 1 1, 2015), "te[r]mos de estar bem a nível pessoal e felizes com o que fazemos" (E 12, 2015), "[...] é o nosso percurso de realização pessoal" (E7, 2015). Fica evidente que, para existir uma carreira de sucesso e poder evoluir, profissionalmente, os trabalhadores têm de fazer o que gostam e sentir-se realizados, quer pessoal quer profissionalmente, pois a carreira engloba todas as áreas da vida do indivíduo.

\section{Considerações finais}

Verifica-se em Portugal uma taxa de desemprego jovem elevada, deparando-se os jovens com empregos precários, atípicos e contratos de trabalho temporário, demonstrando uma grande dificuldade em ingressar no mercado de trabalho, principalmente para os mais qualificados. Vivenciam-se gerações de trabalhadores, muitos deles qualificados, com trabalhos desqualificados e desvalorizados socialmente, com menores direitos profissionais que as gerações anteriores, mas com maior capacidade de resistência à precariedade (LOUÇÃ, 20 12). Nessa perspectiva de precariedade laboral, os Call Centers têm surgido como importantes nichos de emprego para os jovens portugueses, 
verificando-se, pelas entrevistas realizadas, que os motivos de entrada desses trabalhadores foram devido, principalmente, à falta de oportunidades noutras áreas e que a progressão de carreira resulta do seu bom desempenho enquanto operadores.

De acordo com Bono e Bulloni (2008), os Call Centers são cada vez mais usados para satisfazer determinados aspectos da relação com os seus clientes. Desse modo, as tarefas desenvolvidas num Call Center são cada vez mais amplas e complexas. Apesar de a função de operador de call center não exigir qualificações particulares, os entrevistados acreditam que os seus estudos Ihes permitiram desenvolver as funções atuais com sucesso, conseguindo evoluir profissionalmente.

Conforme indicam as investigações de Bono (2000) e Roque (20 13 ), a maioria dos trabalhadores de Call Center são jovens à procura do primeiro emprego ou estudantes universitários, apesar de existirem, cada vez mais, operadores que mantêm essa atividade por vários anos. Muitos desses jovens tiveram necessidade de "ajudar a família" (mesmo que para financiar os seus estudos) (BONO; BULLONI, 2008), verificando-se, também, nessa investigação que muitos ainda coabitam com os progenitores. Apesar disso, alguns, e com o progredir na carreira, emanciparam-se e já residem sozinhos ou com o(a) companheiro(a), tornando-se independentes dos seus progenitores. Mediante o presente estudo, pode-se, igualmente, verificar que alguns dos entrevistadas estão conciliando trabalho com estudos, porém outros, num Call Center, tiveram a sua primeira atividade profissional. $O$ entrevistado que está no Call Center há menos tempo tem mais de um ano de serviço e o que está na área há mais tempo tem 14 anos, sendo que, em média, os entrevistados estão no Call Center há quatro anos.

Pode-se afirmar que a vida profissional tem um lugar importante na vida desses jovens entrevistados, tal como indicado no estudo de Santos e Marques (2006), Roque (2013) e Bono e Bulloni (2008), visto que consideram ter uma relação contratual estável lapesar de o contrato de trabalho ser com empresas de recursos humanos), associada à obtenção de um salário mensal "aceitável" para as condições atuais de Portugal e a um bom ambiente de trabalho. Apesar disso, alguns dos entrevistados ambicionam conseguir trabalhar na sua área de formação e, numa perspectiva a longo prazo, praticamente nenhum se imagina continuar trabalhando em Call Center. Conforme consta no estudo de Santos e Marques (2006), a probabilidade de progressão de 
carreira sentida pelos entrevistados é baixa, considerando que, não atingindo os objetivos propostos, é muito provável que sejam dispensados pelas entidades empregadoras.

De acordo com o estudo de Louçã (2012), os operadores de Call Center têm poucas expectativas de uma carreira prolongada no Call Center, no entanto ele não se passa no caso dos colaboradores a desenvolver trabalho de chefia, uma vez que estes, por norma, gostam do seu trabalho e alguns mantêm ainda a esperança de poder vir a continuar a progredir na empresa. Uma vez que não foram efetivadas entrevistas a operadores, não existem dados que permitam confirmar a parte inicial dessa afirmação, contudo os entrevistados relatam alguma relutância na continuação da ascensão da carreira no Call Center.

Relativamente às condições salariais, conforme estudo de Bono e Bulloni (2008), todos os entrevistados têm uma remuneração fixa associada a uma componente variável (comissões). Ademais, verificou-se, igualmente, nessa análise, que a maioria dos entrevistados se mostra satisfeita com a sua remuneração. No que concerne ao contrato de trabalho, verifica-se que todos os entrevistados possuem um contrato de trabalho a termo indeterminado. Em 94 ambos os casos, o contrato de trabalho não é com a empresa de telecomunicações, mas com empresas de recursos humanos, conforme indicam os estudos de Santos e Marques (2006) e de Kovács (2005). Não se constatou, nessa amostra, qualquer desconforto pelo fato de os entrevistados não terem a sua relação contratual com a empresa de telecomunicações.

Contrariamente ao indicado no estudo de Bono e Bulloni (2008), esses entrevistados não exprimem sentimento de instabilidade, insegurança e insatisfação laboral. Não obstante, alguns entrevistados, principalmente os licenciados, indicam que, a longo prazo, não pretendem continuar no Call Center, tendo esperança de ingressar no mercado de trabalho relacionado à sua formação académica, ressalvando, porém, que, não sabendo o que o futuro thes reserva, esta será sempre uma área onde gostam de trabalhar e na qual, até agora, demonstram obter sucesso.

Conforme Santos e Marques (2006), e contrariamente ao observado por Bono e Bulloni (2008), os entrevistados experienciam companheirismo e solidariedade para com os colegas de trabalho, verificando-se a construção e existência de vínculos sociais e laborais. Pode-se, igualmente, inferir o indicado 
no estudo de Santos e Marques (2006), ou seja, a maioria dos entrevistados sente-se satisfeita com o seu trabalho e considera desenvolver relações de amizade com colegas.

De acordo com Kovács e Castillo (1998), este estudo veio demonstrar que toda a operação do Call Center é controlada, informaticamente, visando obter os melhores resultados possíveis, tornando a produção bastante flexível, automatizada e possuidora de serviços estandardizados para empresas subcontratadas.

Pode-se concluir que, conforme Triper e Dubar (1998 apud ROQUE, 20131, a existência de um emprego estável com carreira profissional garantida é cada vez mais uma utopia num mercado de trabalho que ainda não se adaptou à tendência crescente de licenciados (BONO, 2000) e onde os jovens têm consciência de que as suas condições laborais não são as ideais, procurando a sobrevivência em áreas que nada têm a ver com a sua formação (CORRAL; ISUSI, 2013). Verifica-se que a organização do trabalho de um Call Center é capaz de se adaptar a múltiplas situações. Desse modo, a precariedade imposta pela flexibilidade das relações laborais pode ser entendida como vantagem pelos próprios trabalhadores, visto que podem compatibilizar o trabalho (part time e/ou horários flexíveis) com outros empregos ou projetos pessoais (incluindo estudos). Ou, ainda, porque as expectativas de progressão na carreira justificam a disponibilidade permanente e dedicação ao trabalho, além dos horários e tipo de contrato (LOUÇÃ, 2012). Os Call Centers têm sido uma forma mais facilitada de ingresso no mercado de trabalho, cujos vínculos se pretendiam temporários, no entanto estão se tornando duradouros, sem falar que alguns dos operadores estão seguindo carreira (ROQUE, 2013).

Observa-se, nos relatos dos entrevistados, que o desenvolvimento de uma carreira nessa área de trabalho, apesar de o Call Center não oferecer qualquer garantia futura (emprego de "passagem" ou "transitório"), não é fruto do acaso, mas de um aproveitamento por parte da empresa das competências desses trabalhadores e, por outro prisma, de "aproveitamento" por parte dos trabalhadores dessa oferta de trabalho "aberta", numa altura em que o emprego escasseia. Assim, e de acordo com Minarelli (1995), o indivíduo deve, na gestão da sua carreira, analisar as suas competências e também o mercado da empresa, identificando, depois, onde quer ou pode chegar e qual a meta que se propõe atingir, tendo em vista a realização pessoal e não apenas financeira ou hierárquica. Deve-se conquistar a "empregabilidade 
vitalícia", não o "emprego vitalício", isto é, ser um profissional preparado para novos desafios. Mesmo que, no futuro, os entrevistados não continuem no call center atual, as experiências adquiridas, a "bagagem adquirida", vai, juntamente com outros fatores (pessoais e sociais), desencadear o desenvolvimento das suas carreiras.

Além da criação de emprego, importa aprimorar a sua qualidade, nomeadamente em termos de contratos, níveis salariais, horários de trabalho e prevenção de riscos.

\section{Referências}

ANTUNES, Ricardo; BRAGA, Ruy (Org.). Infoproletários: degradação real do trabalho virtual. São Paulo: Boitempo, 2009.

ASSOCIAÇÃO Portuguesa de Contact Centers (APCC). Estudos de caracterização e benchemarking da atividade de Contact Centres. 2013: Disponível em: http://www. apcontactcenters.org/\#! benchmarketing-apcc/c250t. Acesso em: 8 dez. 2014.

96 BARDIN, Laurence. Análise de conteúdo. Lisboa: Edições 70, 2014.

BECKHARD, Richard. Perfil da organização saudável. São Paulo: Fułura, 1997.

$\mathrm{BONO}$, Andrea del. Call centres, el trabajo del futuro? El caso de estrategias telefonicas, S. A. (ESTATEL). Sociologia del Trabajo, Madrid, n. 39, p. 3-31, mar./maio 2000.

$\mathrm{BONO}$, Andrea del; BULLONI, María Noel. Experiencias laborales juveniles - los agentes telefónicos de call centers offshore en Argentina. Trabajo y Sociedade, Argentina, v. 9, n. 10, p. 1-21, out. 2008.

CARMO, Hermano; FERREIRA, Manuela Malheiro. Metodologia da investigação: guia para auto-aprendizagem. Lisboa: Universidade Aberta, 1998.

CASTANHEIRA, Filipa; CHAMBEL, Maria José. The human resource management in call centres: the development of a questionnaire. Revista de Psicologia del Trabajo y de las Organizaciones, Madrid, v. 28, n. 1, p. 37-50, abr. 2012.

CASTANHEIRA, Lurdes; CAETANO, António. Dimensões do contrato psicológico. Psicologia, v. 13, n. 1-2, p. 99-125, jul./dez.1999. 
CASTELLS, Manuel. La era de la información: la sociedade red. Madrid: Allianza Editorial, 1997.

CEDEFOP. Skills, qualifications and jobs in the EU: the making of a perfect match? evidence from cedefop's european skills and jobs survey. Luxembourg: Publications Office of the European Union, 2015.

CHAMBEL, Maria José; CASTANHEIRA, Filipa. Trabalhar num call center: dos mitos à realidade. Lisboa: Editora RH, 2010.

CORRAL, Antonio; ISUSI, Inigo. Working conditions of young entrants to thelabour market. Dublin: European Foundation for the Improvement of Living and Working Conditions, 2013.

CUNHA, Miguel Pina e; REGO, Arménio; CUNHA, Rita Campos e; CABRAL-CARDOSO, Carlos; MARQUES, Carlos Alves; GOMES, Jorge Filipe da Silva. Manual de gestão de pessoas e do capital humano. 2. ed. Lisboa: Sílabo Edições, 2012.

DUTRA, Joel Souza. Administração de carreiras: uma proposta para repensar a gestão de pessoas. São Paulo: Atlas, 1996.

E2. Entrevista. Porto (Portugal), 12 jan. 2015.

E4. Entrevista. Porto (Portugal), 30 jan. 2015.

E5. Entrevista. Porto (Portugal), 20 fev. 2015.

E7. Entrevista. Porto (Portugal), 5 mar. 2015.

E8. Entrevista. Porto (Portugal), 6 mar. 2015.

E9. Entrevista. Porto (Portugal), 19 mar. 2015.

E10. Entrevista. Porto (Portugal), 24 mar. 2015.

E 11 . Entrevista. Porto (Portugal), 6 abr. 2015.

E12. Entrevista. Porto (Portugal), 9 abr. 2015.

E13. Entrevista. Porto (Portugal), 20 abr. 2015.

EUROSTAT. What it means to be young in the European Uniontoday: facts and figures on youth and children in the EU. 2015.

FERREIRA, Ana Paula Vieira Gomes. Conteúdo e quebra do contracto psicológico e comportamentos individuais de gestão de carreira. 2007. 230f. Tese (Doutorado em Ciências 
Empresariais) - Programa de Pós-Graduação em Ciências Empresariais, Universidade do Minho, Braga, 2007.

GREENHAUS, Jeffrey H.; CALLANAN, Gerard A. Carrer management. 2. ed. Forth Worth: Dryden Press, 1994.

GUERREIRO, Maria das Dores; ABRANTES, Pedro. Transições incertas: os jovens perante o trabalho e a família. Lisboa: Comissão para a lgualdade no Trabalho e no Emprego, 2007.

INSTITUTO NACIONAL DE ESTATÍSTICA. Estatísticas do Empregodo $3^{\circ}$ trimestre de 2014. Lisboa: INE/Estatísticas Oficiais, 2014.

JANEIRO, Isabel Nunes. Motivational Dynamics in the Development of Career Attitudes among Adolescents. Journal of Vocational Behavior, New York, v. 76, n. 2, p. 170-177, apr. 2010.

KOVÁCS, Ilona. El empleo flexible en Portugal. Sociologia del Trabajo, Madrid, n. 45, p. 39-72, mar./maio 2005.

KOVÁCS, Ilona; CASTILLO, Juan. Novos modelos de produção. Oeiras (Portugal): Celta, 1998.

98 LOUÇÃ, João Carlos Anacleto. Nós callcentristas somos o novo proletariado. Identidades e resistências do trabalho em call center. 2012. 121 f. Dissertação (Mestrado em Antropologia) - Programa de Pós-Graduação em Antropologia. Universidade Nova, Lisboa, 2012.

MARTINS, Hélio. Gestão de carreiras na área do conhecimento: abordagem conceitual e resultados de pesquisa. Rio de Janeiro: Qualitymark, 2001.

MINARELLI, José Augusto. Empregabilidade: o caminho das pedras. São Paulo: Editora Gente, 1995.

NÓVOA, António. Vidas de professores. Porto: Porto Editora, 2000.

PINTO, Hugo. Análise da qualidade percebida de um call center: estudo de caso Sage Portugal. 2013. 82f. Dissertação (Mestrado em Gestão de Serviços) - Programa de PósGraduação em Gestão de Serviços, Universidade do Porto, 2013.

RAMOS, Maria da Conceição Pereira. Acção social na área do emprego e da formação profissional. Lisboa: Universidade Aberta, 2003.

REBELO, Glória. Flexibilidade e precariedade no trabalho. Lisboa: Fundação para a Ciência e Tecnologia, 2004. 
ROQUE, IsabelMaria Bonito. A precariedade dos estudantes universitários no universo académico dos Call Centres. International Journal on Working Conditions, Porto, n. 6, p. 18-36, jul./dez. 2013.

SÁ, Vânia Catarina Neves de. O desemprego jovem em Portugal. Dissertação (Mestrado em Economial - Programa de Pós-Graduação em Economia, Universidade de Coimbra, 2014.

SANT'ANNA, Anderson de Souza; CASTILHO, Isolda Velozo; KILIMNIK, Zélia Miranda. Carreiras em transformação e seus paradoxais reflexos nos indivíduos: metáforas de carreira e de competência. Comportamento Organizacional e Gestão, Lisboa, v. 12, n. 2, p. 257 $280,2006$.

SANTOS, Maria João; MARQUES, Ana Paula. $\bigcirc$ caso dos Call Centers -organização do trabalho e atitudes face ao trabalho e emprego. Sociologia, Problemas e Práticas, Oeiras, n. 52, p. 67-86, 2006.

SILVA, Luis Fernando Correa da. Relações de trabalho em call centers: flexibilidade laboral e perfis sócio-ocupacionais em novo cenário de emprego. 2006. 150f. Dissertação (Mestrado em Sociologia) - Programa de Pós-Graduação em Sociologia, Universidade Federal do Rio Grande do Sul, Porto Alegre, 2006.

SOUSA, Maria José; BAPTISTA, Cristina Sales. Como fazer investigação, dissertação, teses e relatórios: segundo Bolonha. Lisboa: Pactor, 2011.

TERENAS, Nuno. O desenvolvimento da carreira. Psicologia.pt: o portal dos psicólogos, 2012. Disponível em:http://www.psicologia.pt/artigos/ver_artigo.php?codigo=A0630. Acesso em: 27 abr. 2015.

WILSON, Tony; DAVIES, Goronwy. The changing career strategies of managers. Career Development International, New York, v. 4, n. 2, p. 101-107, 1999.

Ms. Ana de Fátima Rodrigues Afonso Universidade do Porto | Portugal Faculdade de Economia | FEP Mestrado em Economia e Gestão dos Recursos Humanos E-mail | anitafonso@gmail.com 
Artigo

Carreira num call center: a realidade portuguesa

Profa. Dra. Maria da Conceição Pereira Ramos

Universidade do Porto | Portugal

Faculdade de Economia | FEP

Centro de Estudos das Migrações e Relações Interculturais | CEMRI

E-mail|cramos@fep.up.pt

Recebido 7 mar. 2017

Aceito 17 maio. 2017 